\title{
Predictors of survival after surgery with curative intent for perihilar cholangiocarcinoma
}

\author{
Joachim Geers', Joris Jaekers ${ }^{1}$, Halit Topal', Raymond Aerts', Cindy Vandoren², Guy Vanden Boer ${ }^{1}$ and Baki Topal ${ }^{1 *}$
}

\begin{abstract}
Background: Several clinicopathological predictors of survival after curative surgery for perihilar cholangiocarcinoma (pCCA) have been identified; however, conflicting reports remain. The aim was to analyse clinical and oncological outcomes after curative resection of pCCA and to determine prognostic factors.

Methods: Eighty-eight consecutive patients with pCCA underwent surgery with curative intent between 1998 and 2017. Survival curves were estimated using the Kaplan-Meier method and compared using the log-rank test. Twenty-one prognostic factors were evaluated using multivariate Cox regression models.

Results: Postoperative complications were observed in 73 (83\%) patients of which 41 (47\%) were severe complications (therapy-oriented severity grading system (TOSGS) grade $>2$ ), including a 90-day mortality of $9 \%(n=8)$. Overall survival (OS) and disease-free survival (DFS) rates at 5 and 10 years after surgery were 33\% and 19\%, and 37\% and 30\%, respectively. Independent predictors of OS were locoregional lymph node metastasis (LNM) (risk ratio (RR) 2.12, confidence interval (Cl) 1.19-3.81, $p=0.011$ ), patient American Society of Anesthesiologists (ASA) physical status classification system $>2$ (RR 2.10, Cl 1.03-4.26, $p=0.043)$, and depth of tumour penetration (pT) > 2 (RR 2.58, Cl 1.03$6.30, p=0.043$ ). The presence of locoregional LNM (RR 2.95, Cl 1.51-5.90, $p=0.002$ ) and caudate lobe resection (RR $2.19, \mathrm{Cl} 1.01-5.14, p=0.048$ ) were found as independent predictors of DFS.
\end{abstract}

Conclusions: Curative surgery for pCCA carries high risks with poor long-term survival. Locoregional LNM was the only predictor for both OS and DFS.

Keywords: Biliary tract cancer, Liver resection, Perihilar cholangiocarcinoma, Survival, Prognostic factors

\section{Background}

Perihilar cholangiocarcinoma (pCCA) or Klatskin tumour is a rare malignancy and is defined as an adenocarcinoma that occurs in the biliary tract at the confluence of the hepatic ducts [1]. It has an annual incidence of about 1-2 in 100,000 in Western countries and accounts for up to $50 \%$ of all CCAs [1-3]. Radical surgical resection is the only curative option but has a high

\footnotetext{
*Correspondence: baki.topal@uzleuven.be

'Department of Visceral Surgery, University Hospitals KU Leuven, Herestraat 49, 3000 Leuven, Belgium

Full list of author information is available at the end of the article
}

postoperative morbidity and mortality rate. The 5-year overall survival (OS) ranges from 13 to $42 \%$ for resectable pCCA [4], whereas the median OS of patients with unresectable pCCA is about 12 months with no survivors at 5 years [5]. The poor survival rates after potentially curative surgery are due to cancer recurrence as a result of the aggressive biological behaviour of pCCA with early hematogenous, lymphatic, and perineural spread of cancer cells [6-8]. Postoperative mortality and morbidity rates vary from 5 to $18 \%$ and from 60 to $70 \%$, respectively, which reflect the complexity and technical challenge of the surgical management of pCCA [5]. 
Although several clinicopathological factors have been associated with long-term survival after potentially curative surgery for $\mathrm{pCCA}$, there are conflicting reports regarding these prognostic factors. A recent meta-analysis tried to identify prognostic factors that may determine overall survival after surgery for pCCA, underlining the need for studies to find a homogeneous group of prognostic factors that could be used after potentially curative treatment of patients with pCCA [9]. The aim of the current study was to analyse clinical and oncological outcome of patients with pCCA after surgery with curative intent and to determine prognostic factors for both overall (OS) and disease-free (DFS) survival.

\section{Methods}

\section{Patients}

Between January 1998 and December 2017, a total of 88 consecutive patients underwent a surgical resection with curative intent for histopathologically proven pCCA and were included for further analysis. Data were collected in a prospective database and studied retrospectively. Patients with intrahepatic cholangiocarcinoma, distal cholangiocarcinoma, or gallbladder carcinoma were excluded. The resection margin status was examined and sorted into R0- (microscopic tumour-free margins), R1- (microscopic residual tumour in the margin), and R2-resection status (macroscopic residual tumour in the margin). Patients who underwent a palliative resection (R2-resection) were also excluded from the study population. Patient characteristics are shown in Table 1.

\section{Peri-operative management}

Serum levels of carcinoembryonic antigen (CEA) and carbohydrate antigen 19-9 (CA19-9) were measured at the time of clinical presentation. Preoperative diagnostic imaging consisted of contrast-enhanced computed tomography (CT) scan of the chest and abdomen, and a cholangiogram either by magnetic resonance imaging (MRCP) or by endoscopic retrograde cholangiopancreatography (ERCP). The tumour was classified according to the modified Bismuth-Corlette classification [10].

Biliary drainage before surgery was performed in patients presenting with cholangitis and/or in patients who were expected to need a major hepatectomy and who had a serum total bilirubin level above $5 \mathrm{mg} / \mathrm{dL}$ at the time of presentation. Tumour response to neo-adjuvant systemic chemotherapy was preoperatively evaluated according to the revised RECIST criteria [11]. Postoperative adjuvant systemic chemotherapy was offered to patients who either had an R1-resection or had locoregional lymph node metastasis (LNM), and were fit enough within 3 months postoperative to tolerate chemotherapy.

\section{Resectability}

The main factors that defined resectability were future liver remnant volume and its vascular integrity, and biliary drainage. Major hepatic resection was performed if the preoperative total bilirubin serum level was below 5 $\mathrm{mg} / \mathrm{dL}$. A resection of 3 or more Couinaud segments was considered as major hepatectomy [12].

The decision to define patients as no candidates for resection was made in a multidisciplinary setting and based on Jarnagin's criteria, i.e. metastatic disease, patient factors (medically unfit for surgery, hepatic cirrhosis), and tumour factors (extension to secondary biliary radicles bilaterally, encasement or occlusion of the main portal vein proximal to its bifurcation, atrophy of one hepatic lobe with contralateral portal vein branch encasement or occlusion, atrophy of one hepatic lobe with contralateral tumour extension to secondary biliary radicles, or unilateral tumour extension to secondary biliary radicles with contralateral portal vein encasement or occlusion) [13]. Extra-regional lymph nodes, such as periaortic or peri-caval lymph nodes, which were macroscopically suspicious during surgery, were investigated on frozen section pathology. When found positive for tumour involvement, the patient was considered to have metastatic disease and did not qualify for a curative resection. Histopathological findings were reported according to the 8th TNM classification [14].

\section{Surgical procedure}

Staging laparoscopy with intraoperative laparoscopic ultrasound was done routinely to exclude patients with peritoneal or liver metastases. When a curative resection was considered feasible, laparoscopy was converted to a bilateral subcostal laparotomy. The type and extent of resection depended on the modified Bismuth-Corlette stage [10], the macroscopic involvement of the major blood vessels, and the intraoperative frozen section pathological assessment of the biliary surgical margins. Locoregional lymphadenectomy (hilar, pericholedochal, and hepatoduodenal) was performed routinely. Frozen section pathology was done intraoperatively to examine biliary surgical resection margins. A caudate lobe resection and/or vascular resection (portal vein and/or hepatic artery resection) were done only in case of pre- or intraoperative suspicion of tumour involvement. Intraand postoperative characteristics are shown in Table 2.

\section{Statistical analysis}

Postoperative complications were classified according to the therapy-oriented severity grading system (TOSGS), with severe complications as grade 3 or higher [15]. Classification systems of the International Study Group of Liver Surgery (ISGLS) were used to classify postoperative haemorrhage, liver failure, and bile leaks accordingly 
Table 1 Patient and tumour characteristics

\begin{tabular}{|c|c|c|}
\hline Variables & $\begin{array}{l}n=88 \\
\text { (range, \%) }\end{array}$ & $\begin{array}{l}\text { Missing data, } n \\
(\%)\end{array}$ \\
\hline Age (years, median, range) & $64(30-80)$ & $0(0)$ \\
\hline Gender & & $0(0)$ \\
\hline Male & $52(59)$ & \\
\hline Female & $36(40)$ & \\
\hline BMI (kg/m², median, range) & $\begin{array}{l}24.54(17.6- \\
35.4)\end{array}$ & $8(9)$ \\
\hline ASA & & $0(0)$ \\
\hline 1 & $6(7)$ & \\
\hline 2 & $53(60)$ & \\
\hline 3 & $29(33)$ & \\
\hline Cholangitis & $12(14)$ & $0(0)$ \\
\hline Biliary drainage & $56(64)$ & $0(0)$ \\
\hline Endoscopic & $44(50)$ & \\
\hline Percutaneous transhepatic & $2(2)$ & \\
\hline Both & $10(11)$ & \\
\hline CEA serum level ( $\mu \mathrm{g} / \mathrm{L})$ & $2.55(0.7-18.8)$ & $50(57)$ \\
\hline CA19-9 serum level (kU/L) & $151(1-3215)$ & $36(41)$ \\
\hline Bismuth-Corlette classification & & $0(0)$ \\
\hline Type I & $12(14)$ & \\
\hline Type II & $19(22)$ & \\
\hline Type IIla & $20(23)$ & \\
\hline Type IIIb & $25(28)$ & \\
\hline Type IV & $12(14)$ & \\
\hline Pathological T-stage & & $0(0)$ \\
\hline Tis & $1(1)$ & \\
\hline T1 & $12(14)$ & \\
\hline $\mathrm{T} 2$ & $65(74)$ & \\
\hline T3 & $6(7)$ & \\
\hline T4 & $4(5)$ & \\
\hline Pathological N-stage & & $4(5)$ \\
\hline pNO & $46(52)$ & \\
\hline pN1 & $33(38)$ & \\
\hline pN2 & $5(6)$ & \\
\hline Differentiation grade & & $24(27)$ \\
\hline Well (G1) & $20(23)$ & \\
\hline Moderate (G2) & $30(34)$ & \\
\hline Poor (G3) & $14(16)$ & \\
\hline $\begin{array}{l}\text { Tumour diameter (mm, median, } \\
\text { range) }\end{array}$ & $26(10-80)$ & $19(22)$ \\
\hline $\begin{array}{l}\text { Total number of lymph nodes } \\
\text { (median, range) }\end{array}$ & $8(1-22)$ & $7(8)$ \\
\hline $\begin{array}{l}\text { Positive lymph nodes (median, } \\
\text { range) }\end{array}$ & $2(1-13)$ & $1(1)$ \\
\hline ECLNI & $14(16)$ & $1(1)$ \\
\hline Perineural invasion & $69(78)$ & $2(2)$ \\
\hline
\end{tabular}

Table 1 Patient and tumour characteristics (Continued)

\begin{tabular}{lll}
\hline Variables & $\begin{array}{l}\boldsymbol{n}=\mathbf{8 8} \\
\text { (range, \%) }\end{array}$ & $\begin{array}{l}\text { Missing data, } \boldsymbol{n} \\
\text { (\%) }\end{array}$ \\
\hline $\begin{array}{l}\text { Resection margin } \\
\text { R0 }\end{array}$ & $0(0)$ \\
R1 & $74(84)$ & \\
PRM & $14(16)$ & \\
$\quad \leq 1 \mathrm{~mm}$ & & $38(43)$ \\
$>1 \mathrm{~mm}$ & 36 & \\
\hline
\end{tabular}

$\overline{B M I}$ body mass index, ASA American Society of Anesthesiologists physical status classification system, CEA carcinoembryonic antigen, CA carbohydrate antigen, Tis tumour in situ, ECLNI extracapsular lymph node involvement, $p R M$ magnitude of tumour-free resection margin

[16-18]. The Kaplan-Meier estimates were used for survival analysis. Overall survival (OS) was defined as time from surgery to date of death. Disease-free survival (DFS) was defined as time from surgery to date of any cancer recurrence or death. Patients were followed up until death or until the date of study closure in December 2018 , resulting in a median follow-up time of $23(0-236)$ months. Locoregional recurrence was defined as cancer recurrence at the surgical resection site or at the liver hilum. Cancer recurrence more distant in the liver or at other distant sites was defined as metastatic or distant recurrence.

A set of 21 potential prognostic factors were analysed: patient age (years), gender (male/female), body mass index (BMI), American Society of Anesthesiologists (ASA) physical status classification system, the year of diagnosis/surgery (dichotomised in 10- and 5-year groups), presence of cholangitis, preoperative total bilirubin serum level, tumour depth invasion (pT), locoregional LNM $(\mathrm{pN}+)$, tumour differentiation grade $(\mathrm{pG})$, tumour diameter $(\mathrm{mm})$, extracapsular lymph node involvement (ECLNI), microvascular invasion, macrovascular invasion, perineural invasion, R-status (R0/R1), magnitude of tumour-free resection margin (pRM), intraoperative transfusion, caudate lobe resection, major hepatectomy, and portal vein resection. Variables missing more than $20 \%$ of data were excluded from multivariate analysis. Multivariate analyses were done using the Cox proportional hazards model. A $p$ value of $<0.05$ was considered statistically significant. Statistical analyses were done using the software package JMP for Mac, version 14 (SAS Institute Inc., Cary, NC, USA).

\section{Results}

Patients

All patient and tumour characteristics are shown in Table 1. Median age was 64years (range 30-80), and male-to-female ratio was 1.4:1. Fifty-eight (66\%) patients presented with obstructive jaundice, 12 (14\%) patients had cholangitis, 11 (13\%) patients had a cholestasis- 
Table 2 Intraoperative and postoperative characteristics

Variable

Staging laparoscopy

Type of surgery

Left hepatectomy

Right hepatectomy

Central hepatectomy

Extended left hepatectomy

Extended right hepatectomy

Bile duct resection

Segmental hepatectomy and bile duct resection

Caudate lobe resection

Common hepatic artery resection

Portal vein resection

Duration of surgery (minutes, median, range)

Intraoperative blood loss ( $\mathrm{mL}$, median, range)

Intraoperative transfusion

Pringle manoeuvre performed

Total duration (minutes, median, range)

Intraoperative complication

Postop ICU admission

Length of ICU stay (days, median, range)

TOSGS > 2 (excl. mortality)

Postoperative haemorrhage

ISGLS grade B

ISGLS grade C

Liver failure

ISGLS grade A

ISGLS grade $B$

ISGLS grade $C$

Bile leak

ISGLS grade A

ISGLS grade $B$

ISGLS grade C

Postoperative blood transfusion

Postoperative complications

Intra-abdominal abscess

Sepsis

Portal thrombosis

Pulmonary complication

Cardiac complication

Multiple organ failure

Reoperation

In-hospital mortality

90-day mortality

Length of hospital stay (days, median, range) n $=88$ (range, \%)

78 (89)

Mssing data, $n(\%)$

$0(0)$

$0(0)$

29 (33)

26 (30)

4 (5)

$2(2)$

$2(2)$

23 (26)

$2(2)$

56 (64)

$0(0)$

3 (3)

$0(0)$

$18(20)$

$0(0)$

240 (140-360)

$62(71)$

$900(50-12000)$

47 (53)

38 (43)

$0(0)$

8 (9)

1 (1)

25 (10-45)

2 (2)

$20(23)$

$0(0)$

16 (18)

$0(0)$

$4(1-13)$

$0(0)$

33 (38)

$0(0)$

0 (0)

5 (6)

5 (6)

$1(1)$

2 (2)

5 (6)

2 (2)

18 (21)

5 (6)

34 (39)

0 (0)

$0(0)$

25 (28)

$0(0)$

5 (6)

4 (5)

12 (14)

4 (4)

4 (4)

13 (15)

0 (0)

8 (9)

$0(0)$

8 (9)

0 (0)

18 (3-94) 
Table 2 Intraoperative and postoperative characteristics (Continued)

\begin{tabular}{lll}
\hline Variable & $\mathbf{n = 8 8}$ (range, \%) & Missing data, $\boldsymbol{n}(\%)$ \\
\hline Readmission within 30 days of discharge & $12(14)$ & $0(0)$ \\
Any recurrence & $42(48)$ & $0(0)$ \\
Locoregional recurrence & $18(21)$ & $0(0)$ \\
Location of first metastatic recurrence & $39(44)$ & $13(15)$ \\
Liver & $12(14)$ & $3(3)$ \\
Peritoneum & $6(7)$ & $2(2)$ \\
Pulmonary & $2(2)$ \\
Retroperitoneal lymph nodes & $1(1)$ \\
Pancreas & Abdominal wall muscle & \\
Colon &
\end{tabular}

ICU intensive care unit, TOSGS therapy-oriented severity grading scale, ISGLS International Study Group of Liver Surgery

related blood panel, 5 (6\%) patients complained of vague abdominal discomfort with weight loss, and $2(2 \%)$ patients were diagnosed during the follow-up of another malignancy. One patient (1\%) had an underlying primary sclerosing cholangitis.

\section{Peri-operative management}

The median CEA was $2.6 \mu \mathrm{g} / \mathrm{L}$ (range $0.7-18.8$, reference value $<3.8 \mu \mathrm{g} / \mathrm{L}$ ), and the median CA19-9 was $151 \mathrm{kU} / \mathrm{L}$ (range 1-3215, reference value $<34 \mathrm{kU} / \mathrm{L}$ ). Forty-four (50\%) patients underwent an internal endo-biliary stent via ERCP, 2 (2\%) patients had an external drainage via percutaneous transhepatic biliary approach, and 10 (11\%) patients were managed with a combination of ERCP and percutaneous approach. Preoperative portal vein embolisation was performed in one patient (1\%).

Cisplatin-based systemic chemotherapy prior to surgery was given in 3 patients (3\%), resulting in either partial response $(n=1)$ or stable disease $(n=2)$, evaluated according to the revised RECIST criteria [11].

The types of surgical resections are listed in Table 2. The caudate lobe was resected in 56 (64\%) patients. Resection of the main portal vein or the contralateral portal vein (contralateral to the hepatectomy) was done in $18(20 \%)$ patients. Histopathological R0-resection was obtained in 74 (84\%) patients. All procedures were performed by one of the two hepatobiliary surgeons.

Adjuvant gemcitabine or gemcitabine plus cisplatin was given to $13(15 \%)$ patients. Within this subgroup, 10 patients had locoregional LNM and 3 patients had an R1-resection. One of the latter patients also received adjuvant radiotherapy. The majority of patients $(n=36)$ who met the criteria to receive adjuvant therapy (R1-resection $n=5$, locoregional LNM $n=$ 25 , both R1-resection and locoregional LNM $n=6$ ) were excluded because they were considered not fit enough to tolerate chemotherapy within the first 3 months postoperative.

\section{Postoperative outcome}

Postoperative complications were observed in 73 (83\%) patients, including 8 (9\%) in-hospital deaths and $33(38 \%)$ severe complications (TOSGS > 2). The 90-day mortality was the same as the in-hospital mortality $(n=8,9 \%)$. Causes of postoperative mortality were liver failure $(n=3)$, cardiac arrest $(n=2)$, haemorrhage $(n=1)$, pulmonary embolism $(n=1)$, and undetermined $(n=1)$. Indications for reoperation were bleeding $(n=5)$, biliary fistula $(n=4)$, abscess $(n=3)$, and thoracic empyema $(n=1)$. Postoperative characteristics are shown in Table 2.

\section{Survival and prognostic factors}

Median OS was 30.9 months (range 22.8-44.2). The 1-, $3-, 5-$, and 10-year OS rates were $76 \%, 47 \%, 33 \%$, and $19 \%$, respectively. Median DFS time was 28.7 months (range 19.5-52.2). The 1-, 3-, 5-, and 10-year DFS rates were $82 \%, 45 \%, 37 \%$, and $30 \%$, respectively.

In univariable analyses, several potential prognostic factors were significantly related to OS (Table 3 ) or DFS (Table 4). In multivariable analyses, the presence of locoregional LNM (RR 2.12, CI 1.19-3.81, $p=0.011$ ), patient ASA score $>2$ (RR 2.10, CI 1.03-4.26, $p=$ 0.043 ), and pT-stage $>2$ (RR 2.58, CI 1.03-6.30, $p=$ 0.011 ) were found as independent predictors of poor OS. $\mathrm{pN}+(\mathrm{RR} 2.95, \mathrm{CI} 1.51-5.90, p=0.002)$ and caudate lobe resection (RR 2.19, CI 1.01-5.14, $p=0.048$ ) were found as independent predictors of DFS. The KaplanMeier estimates for OS and DFS for both pNO and pN+ subgroups are shown in Fig. 1. The 5-year OS for patients with pN0 was $46 \%$ as compared to $14 \%$ for patients with $\mathrm{pN}+(p<0.002)$. The 5 -year DFS for patients with $\mathrm{pN} 0$ was $55 \%$, compared to $12 \%$ for $\mathrm{pN}+$ patients 
Table 3 Results of univariable and multivariable analyses for overall survival

\begin{tabular}{|c|c|c|c|c|c|}
\hline \multirow[t]{2}{*}{ Parameter } & & \multirow{2}{*}{$\begin{array}{l}\text { No. of } \\
\text { patients }\end{array}$} & \multirow{2}{*}{$\begin{array}{l}\text { Univariable } \\
p \text { value }\end{array}$} & \multicolumn{2}{|l|}{ Multivariable } \\
\hline & & & & Risk ratio $(95 \% \mathrm{Cl})$ & $p$ value \\
\hline \multicolumn{6}{|l|}{ Patient-related } \\
\hline Age & & 88 & 0.764 & $1.61(0.36-7.91)$ & 0.539 \\
\hline \multirow[t]{2}{*}{ Gender } & Male & 52 & 0.583 & $1.21(0.64-2.24)$ & 0.555 \\
\hline & Female & 36 & & & \\
\hline BMI & & 80 & 0.910 & & \\
\hline \multirow[t]{2}{*}{ ASA } & $>2$ & 29 & 0.017 & $2.10(1.03-4.25)$ & 0.043 \\
\hline & $\leq 2$ & 59 & & & \\
\hline \multirow[t]{2}{*}{ Year of diagnosis (10 years) } & 1998-2007 & 33 & 0.533 & & \\
\hline & $2008-2017$ & 55 & & & \\
\hline \multirow[t]{4}{*}{ Year of diagnosis (5 years) } & 1998-2002 & 14 & 0.932 & & \\
\hline & 2003-2007 & 19 & & & \\
\hline & 2008-2012 & 30 & & & \\
\hline & 2013-2017 & 25 & & & \\
\hline \multirow[t]{2}{*}{ Cholangitis } & Yes & 12 & 0.971 & & \\
\hline & No & 76 & & & \\
\hline Serum level of total bilirubin at presentation & & 88 & 0.098 & & \\
\hline \multicolumn{6}{|l|}{ Tumour-related } \\
\hline \multirow[t]{2}{*}{ Pathological T-stage } & $>$ pT2 & 10 & 0.002 & $2.58(1.03-6.30)$ & 0.043 \\
\hline & $\leq \mathrm{pT} 2$ & 78 & & & \\
\hline \multirow[t]{2}{*}{ Pathological N-stage } & $\mathrm{pN}+$ & 38 & $<0.002$ & $2.12(1.19-3.80)$ & 0.011 \\
\hline & pNo & 46 & & & \\
\hline \multirow[t]{3}{*}{ Differentiation grading } & 1 & 20 & 0.025 & & \\
\hline & 2 & 30 & & & \\
\hline & 3 & 14 & & & \\
\hline Tumour size (mm) & & 69 & 0.660 & & \\
\hline \multirow[t]{2}{*}{ ECLNI } & Yes & 14 & 0.736 & & \\
\hline & No & 25 & & & \\
\hline \multirow[t]{2}{*}{ Microvascular invasion } & Yes & 59 & 0.769 & & \\
\hline & No & 22 & & & \\
\hline \multirow[t]{2}{*}{ Macrovascular invasion } & Yes & 20 & 0.041 & $1.63(0.09-8.27)$ & 0.660 \\
\hline & No & 68 & & & \\
\hline \multirow[t]{2}{*}{ Perineural invasion } & Yes & 69 & 0.238 & & \\
\hline & No & 17 & & & \\
\hline \multirow[t]{2}{*}{ R-status } & 1 & 14 & 0.318 & & \\
\hline & 0 & 74 & & & \\
\hline \multirow[t]{2}{*}{ pRM } & $\leq 1 \mathrm{~mm}$ & 36 & 0.127 & & \\
\hline & $>1 \mathrm{~mm}$ & 14 & & & \\
\hline \multicolumn{6}{|l|}{ Surgery-related } \\
\hline \multirow[t]{2}{*}{ Intraoperative transfusion } & Yes & 38 & 0.006 & $1.58(0.89-2.83)$ & 0.121 \\
\hline & No & 50 & & & \\
\hline \multirow[t]{2}{*}{ Caudate lobe resection } & Yes & 56 & 0.111 & & \\
\hline & No & 32 & & & \\
\hline Major hepatectomy & Yes & 63 & 0.715 & & \\
\hline
\end{tabular}


Table 3 Results of univariable and multivariable analyses for overall survival (Continued)

\begin{tabular}{|c|c|c|c|c|c|}
\hline \multirow[t]{2}{*}{ Parameter } & & \multirow{2}{*}{$\begin{array}{l}\text { No. of } \\
\text { patients }\end{array}$} & \multirow{2}{*}{$\begin{array}{l}\text { Univariable } \\
p \text { value }\end{array}$} & \multicolumn{2}{|l|}{ Multivariable } \\
\hline & & & & Risk ratio $(95 \% \mathrm{CI})$ & $p$ value \\
\hline & No & 25 & & & \\
\hline \multirow[t]{2}{*}{ Portal vein resection } & Yes & 18 & 0.020 & $0.78(0.13-15.17)$ & 0.828 \\
\hline & No & 70 & & & \\
\hline
\end{tabular}

$R R$ risk ratio, $C l$ confidence interval, $B M I$ body mass index, $A S A$ American Society of Anesthesiologists physical status classification system, ECLNI extracapsular lymph node involvement, $p R M$ magnitude of tumour-free resection margin, $A J C C$ American Joint Committee on Cancer

$(p<0.0001)$. In $35 \%$ of patients with $\mathrm{pN}+$, cancer recurrence was observed within a year after surgery. In patients with pN0, less than $5 \%$ had a recurrence within a year.

\section{Discussion}

In this retrospective cohort study, surgery with curative intent for pCCA was associated with 5- and 10-year OS rates of $33 \%$ and $19 \%$, and with 5- and 10-year DFS rates of $37 \%$ and $30 \%$, respectively. These results are in line with current literature $[5,7,13,19-29]$. The 5-year OS rates of these larger series range from 22 to $44 \%$. Fiveyear DFS rates range from 12 to $32 \%$; however, the majority of these studies did not report 5-year DFS rates. Moreover, some of these series also included patients with an R2-resection and the use of (neo-)adjuvant treatment is non-standardised. This makes an adequate comparison between these series difficult. The presence of locoregional LNM $(\mathrm{pN}+)$, tumour invasion depth $(\mathrm{pT})$, and ASA score were found to be independent predictors of OS. The presence of locoregional LNM and caudate lobe resection had a negative influence on DFS.

The negative impact of locoregional LNM on survival has already been well-established $[4,8,9,19,23,25,27$, 29-36]. In the current study, the 5-year DFS of patients without LNM was $55 \%$, compared to $12 \%$ of patients with LNM. About a third (35\%) of patients with LNM developed cancer recurrence within a year after surgery, whereas cancer recurrence occurred in less than $5 \%$ of patients without LNM. These observations provide some support for the statement by Groot Koerkamp et al. that patients with LNM have less chance to be cured [34]. However, in the series of Buettner et al., patients with LNM who underwent a resection still seem to have a better survival after resection compared to patients without surgery [36]. The pT-stage of the AJCC/UICC TNM-staging system was already identified as a prognostic factor $[4,8,9,20,23,29,32]$. In our cohort, pTstage was a predictor of OS, but had no effect on DFS.

Several authors support a caudate lobe resection in order to achieve R0-resection and improve survival [21, $22,24,37,38]$. In the present study, caudate lobe resection was associated with worse DFS. As we only performed caudate lobe resection in case of suspected tumour involvement, this subgroup of patients may represent a more advanced stage of disease. Despite not performing a routine caudate lobe resection, the $84 \%$ R0-resection rate in our study seems to be higher than that in the literature, which ranges from 31 to $71 \%$ [21, $22,37,38]$. However, comparison of our R0-resection status with that in the literature would be methodologically wrong as there are many differences in study populations [24].

In the current study, R0-resection status did not affect OS nor DFS, despite being considered in the literature as one of the primary predictors of survival $[4,7,13$, 19-23, 25-27, 30, 32, 34, 35, 37, 39, 40]. These findings might be explained by the rather small number of patients $(n=88)$ and the relatively low rate of R1-resection $(16 \%)$ in our study. Moreover, as some patients $(n=3)$ with R1-resection received adjuvant chemotherapy, these results might be biassed. In a recent meta-analysis, the resection margin status had a significant effect on OS but high heterogeneity was reported [9]. Comparable to our findings, Lurje et al. reported that R1-resection was not associated with an impaired outcome [29]. The series of Lee et al. also showed no significant difference for both 3- and 5-year overall survival between patients in the R0-resection group and patients in the R1resection group [33].

The simultaneous resection of the main or contralateral portal vein was not a predictor of survival in our cohort. We only performed a (main or contralateral) portal vein resection in selected cases, when tumour involvement was suspected. In the trend towards a more aggressive and radical surgical approach for pCCA, an obligatory portal vein resection is advocated by Neuhaus et al. [24]. They state that a 'hilar-en-bloc resection' (right trisectionectomy and concomitant portal vein resection) is oncologically superior for pCCA and reported a 5 -year survival of $58 \%$ in the hilar-en-bloc resection group. However, they only included patients who had an R0-resection for this survival analysis. A portal vein resection is considered to be safe and feasible, but some authors report that it is associated with an increased complication and mortality rate $[41,42]$.

Regarding the clinical outcomes, there was a major morbidity rate (TOSGS > 2) of $38 \%$ and mortality rate of 9\%. These are comparable to both Eastern and Western high-volume centres with morbidity rates between 30 
Table 4 Results of univariable and multivariable analyses for disease-free survival

\begin{tabular}{|c|c|c|c|c|c|}
\hline \multirow[t]{2}{*}{ Parameter } & & \multirow{2}{*}{$\begin{array}{l}\text { No. of } \\
\text { patients }\end{array}$} & \multirow{2}{*}{$\begin{array}{l}\text { Univariable } \\
p \text { value }\end{array}$} & \multicolumn{2}{|l|}{ Multivariable } \\
\hline & & & & Risk ratio $(95 \% \mathrm{Cl})$ & $p$ value \\
\hline \multicolumn{6}{|l|}{ Patient-related } \\
\hline Age & & 88 & 0.096 & $1.08(0.22-5.60)$ & 0.926 \\
\hline \multirow[t]{2}{*}{ Gender } & Male & 52 & 0.617 & $1.10(0.57-2.08)$ & 0.771 \\
\hline & Female & 36 & & & \\
\hline BMI & & 80 & 0.390 & & \\
\hline \multirow[t]{2}{*}{ ASA } & $>2$ & 29 & 0.864 & & \\
\hline & $\leq 2$ & 59 & & & \\
\hline \multirow[t]{2}{*}{ Year of diagnosis (10 years) } & 1998-2007 & 33 & 0.921 & & \\
\hline & 2008-2017 & 55 & & & \\
\hline \multirow[t]{4}{*}{ Year of diagnosis (5 years) } & 1998-2002 & 14 & 0.256 & & \\
\hline & 2003-2007 & 19 & & & \\
\hline & 2008-2012 & 30 & & & \\
\hline & 2013-2017 & 25 & & & \\
\hline \multirow[t]{2}{*}{ Cholangitis } & Yes & 12 & 0.217 & & \\
\hline & No & 76 & & & \\
\hline Serum level of total bilirubin at presentation & & 88 & 0.288 & & \\
\hline \multicolumn{6}{|l|}{ Tumour-related } \\
\hline \multirow[t]{2}{*}{ Pathological T-stage } & $\geq \mathrm{pT3}$ & 10 & 0.100 & $0.88(0.29-2.41)$ & 0.813 \\
\hline & $\leq \mathrm{pT} 2$ & 78 & & & \\
\hline \multirow[t]{2}{*}{ Pathological N-stage } & $\mathrm{pN}+$ & 38 & $<0.0001$ & $2.95(1.51-5.90)$ & 0.002 \\
\hline & pNO & 46 & & & \\
\hline \multirow[t]{3}{*}{ Differentiation grading } & 1 & 20 & 0.275 & & \\
\hline & 2 & 30 & & & \\
\hline & 3 & 14 & & & \\
\hline Tumour size (mm) & & 69 & 0.510 & & \\
\hline \multirow[t]{2}{*}{ ECLNI } & Yes & 14 & 0.558 & & \\
\hline & No & 25 & & & \\
\hline \multirow[t]{2}{*}{ Microvascular invasion } & Yes & 59 & 0.507 & & \\
\hline & No & 22 & & & \\
\hline \multirow[t]{2}{*}{ Macrovascular invasion } & Yes & 20 & 0.021 & $3.11(0.00-3.37)$ & 0.273 \\
\hline & No & 68 & & & \\
\hline \multirow[t]{2}{*}{ Perineural invasion } & Yes & 69 & 0.241 & & \\
\hline & No & 17 & & & \\
\hline \multirow[t]{2}{*}{ R-status } & 1 & 14 & 0.455 & & \\
\hline & 0 & 74 & & & \\
\hline \multirow[t]{2}{*}{ pRM } & $\leq 1 \mathrm{~mm}$ & 36 & 0.002 & & \\
\hline & $>1 \mathrm{~mm}$ & 14 & & & \\
\hline \multicolumn{6}{|l|}{ Surgery-related } \\
\hline \multirow[t]{2}{*}{ Intraoperative transfusion } & Yes & 38 & 0.109 & & \\
\hline & No & 50 & & & \\
\hline \multirow[t]{2}{*}{ Caudate lobe resection } & Yes & 56 & 0.006 & $2.19(1.01-5.14)$ & 0.048 \\
\hline & No & 32 & & & \\
\hline Major hepatectomy & Yes & 63 & 0.260 & & \\
\hline
\end{tabular}


Table 4 Results of univariable and multivariable analyses for disease-free survival (Continued)

\begin{tabular}{|c|c|c|c|c|c|}
\hline \multirow[t]{2}{*}{ Parameter } & & \multirow{2}{*}{$\begin{array}{l}\text { No. of } \\
\text { patients }\end{array}$} & \multirow{2}{*}{$\begin{array}{l}\text { Univariable } \\
p \text { value }\end{array}$} & \multicolumn{2}{|l|}{ Multivariable } \\
\hline & & & & Risk ratio $(95 \% \mathrm{Cl})$ & $p$ value \\
\hline & No & 25 & & & \\
\hline \multirow[t]{2}{*}{ Portal vein resection } & Yes & 18 & 0.002 & $1.63(0.50-2.01)$ & 0.148 \\
\hline & No & 70 & & & \\
\hline
\end{tabular}

$R R$ risk ratio, $C l$ confidence interval, $B M I$ body mass index, $A S A$ American Society of Anesthesiologists physical status classification system, ECLNI extracapsular lymph node involvement, $p R M$ magnitude of tumour-free resection margin, AJCC American Joint Committee on Cancer

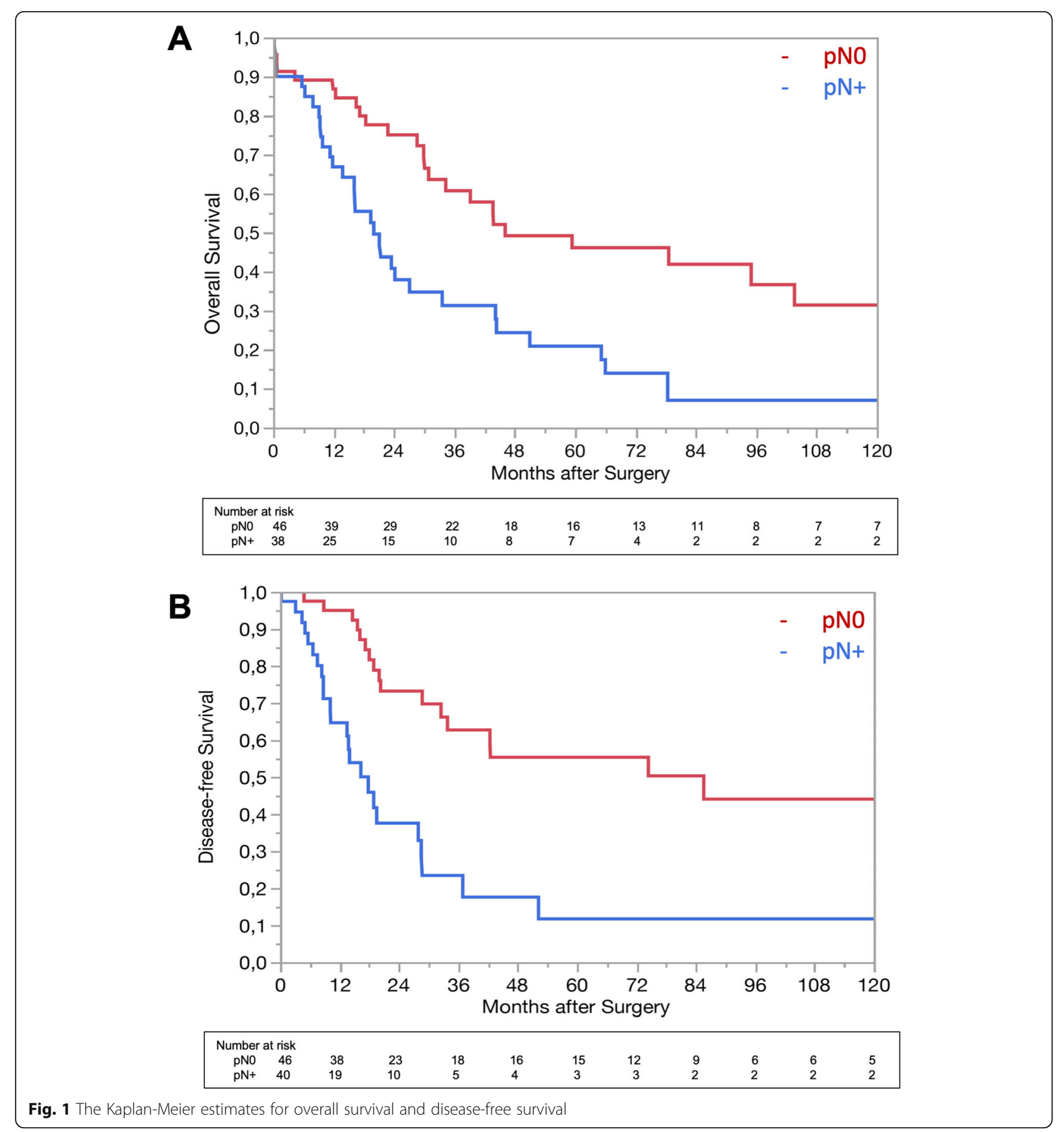


and $68 \%$ and mortality rates ranging from 2 to $13 \%[5,7$, 13, 19-29]. The largest contributing factor to the morbidity in our cohort was biliary leakage (ISGLS grade B) and intra-abdominal abscesses requiring drainage. Most of the patients in our study population who died, did so due to liver failure $(n=3)$, which is consistent with the literature [2].

Strengths of this study include its homogeneous study population and long-term follow-up. Most previous reports include patients with intrahepatic or distal CCA, or even gallbladder cancer as well, despite the fact these pathologies are considered to have different behaviour and biology. The current study is however limited by its retrospective design and restricted sample size. Considering the low incidence of pCCA, acquiring a large single-centre cohort is difficult. Despite the homogenous study population, there is still heterogeneity present regarding the surgical procedures. Moreover, because of the long study period, there was no standardised use of (neo-)adjuvant treatment for pCCA, making the interpretation of results difficult.

\section{Conclusions}

Curative surgery for perihilar cholangiocarcinoma remains a high-risk procedure with poor long-term survival. Locoregional LNM was the only significant prognostic factor to determine both OS and DFS.

\footnotetext{
Abbreviations

AJCC: American Joint Committee on Cancer; ASA: American Society of Anesthesiologists; BMI: Body mass index; CA19-9: Carbohydrate antigen 19-9; CEA: Carcinoembryonic antigen; Cl: Confidence interval; DFS: Disease-free survival; ECLNI: Extracapsular lymph node involvement; ERCP: Endoscopic retrograde cholangiopancreatography; ICU: Intensive care unit; ISGL S: International Study Group of Liver Surgery; LNM: Lymph node metastasis; MRCP: Magnetic resonance cholangiopancreatography; OS: Overall survival; pCCA: Perihilar cholangiocarcinoma; pRM: Pathological resection margin; RECIST: Response evaluation criteria in solid tumours; RR: Risk ratio; Tis: Tumour in situ; TOSGS: Therapy-oriented severity grading scale; UICC: Union for International Cancer Control
}

\section{Acknowledgements}

None.

\section{Authors' contributions}

JG and BT designed the study, collected the data, and wrote the manuscript. CVD and GVB helped with the data acquisition. RA, JJ, and HT helped with the interpretation of the data and were involved in the drafting of the manuscript and revising it critically. The statistical analysis was done by BT. All authors read and approved the final manuscript. All authors agreed to be accountable for all aspects of the work.

\section{Funding}

No funding was received for this research.

\section{Availability of data and materials}

The datasets used and/or analysed during the current study are available from the corresponding author on reasonable request.

\section{Ethics approval and consent to participate}

All procedures performed in this study involving the patients were in accordance with the ethical standards of the institutional and the national research committee and with the 1964 Helsinki Declaration and its later amendments or comparable ethical standards. The medical ethics committee of our institution (University Hospitals Leuven) waived the need for review of the study due to its observational and retrospective nature.

\section{Consent for publication}

Not applicable.

\section{Competing interests}

The authors declare that they have no competing interests.

\section{Author details}

${ }^{1}$ Department of Visceral Surgery, University Hospitals KU Leuven, Herestraat 49, 3000 Leuven, Belgium. ²Management Information \& Registration, University Hospitals KU Leuven, Herestraat 49, 3000 Leuven, Belgium.

Received: 15 May 2020 Accepted: 21 October 2020

Published online: 03 November 2020

\section{References}

1. Valle J, Borbath I, Khan SA, Huguet F, Gruenberger T. ESMO Guideline Committee. Biliary cancer: ESMO Clinical Practice Guidelines for diagnosis, treatment and follow up. Ann Oncol. 2016 Sep;27(suppl 5):v28-37.

2. Groot Koerkamp B, Jarnagin WR. Surgery for perihilar cholangiocarcinoma Br J Surg. 2018;105(7):771-2.

3. Groot Koerkamp B, Fong Y. Outcomes in biliary malignancy. J Surg Oncol. 2014;110(5):585-91.

4. Tang Z, Yang Y, Zhao Z, Wei K, Meng W, Li X. The clinicopathological factors associated with prognosis of patients with resectable perihilar cholangiocarcinoma: a systematic review and meta-analysis. Medicine (Baltimore). 2018;97(34):e11999.

5. Rassam F, Roos E, van Lienden $K P$, van Hooft JE, Klümpen HJ, van Tienhoven $\mathrm{G}$, et al. Modern work-up and extended resection in perihilar cholangiocarcinoma: the AMC experience. Langenbecks Arch Surg. 2018; 403(3):289-307.

6. Burke EC, Jarnagin WR, Hochwald SN, Pisters PW, Fong Y, Blumgart LH. Hilar cholangiocarcinoma: patterns of spread, the importance of hepatic resection for curative operation, and a pre-surgical clinical staging system. Ann Surg. 1998:228:385-94.

7. Saxena A, Chua TC, Chu FC, Morris DL. Improved outcomes after aggressive surgical resection of hilar cholangiocarcinoma: a critical analysis of recurrence and survival. Am J Surg. 2011;202:310-20.

8. Hu H, Jin Y, Shrestha A, Ma W, Wang J, Liu F, et al. Predictive factors of early recurrence after $\mathrm{RO}$ resection of hilar cholangiocarcinoma: a single institution experience in China. Cancer Med. 2019;8(4):1567-75.

9. Bird NTE, McKenna A, Dodd J, Poston G, Jones R, Malik H. Meta-analysis of prognostic factors for overall survival in patients with resected hilar cholangiocarcinoma. Br J Surg. 2018;105(11):1408-16.

10. Bismuth $\mathrm{H}$, Nakache $\mathrm{R}$, Diamond T. Management strategies in resection for hilar cholangiocarcinoma. Ann Surg. 1992;215:31-8.

11. Eisenhauer E, Therasse P, Bogaerts J, Schwartz LH, Sargent D, Ford R, et al. New response evaluation criteria in solid tumours: revised RECIST guideline (version 1.1). Eur J Cancer. 2009;45(2):228-47.

12. Couinaud C. Lobes et segments hepatiques; notes sur l'architecture anatomique et chirurgicale du foie. Presse Med. 1954;62:709-12.

13. Jarnagin WR, Fong Y, DeMatteo RP, Gonen M, Burke EC, Bodniewicz J, et al. Staging, resectability, and outcome in 225 patients with hilar cholangiocarcinoma. Ann Surg. 2001;234(4):507-19.

14. Brierley J, Gospodarowicz M, Wittekind C. UICC TNM classification of malignant tumours. 8th ed. Chichester: Wiley; 2017.

15. Dindo D, Demartines N, Clavien PA. Classification of surgical complications: a new proposal with evaluation in a cohort of 6336 patients and results of a survey. Ann Surg. 2004:240:214-5.

16. Rahbari NN, Garden OJ, Padbury R, Maddern G, Koch M, Hugh TJ, et al. Post-hepatectomy haemorrhage: a definition and grading by the International Study Group of Liver Surgery (ISGLG). HPB (Oxford). 2011;13: 528-35.

17. Rahbari NN, Garden OJ, Padbury R, Brooke-Smith M, Crawford M, Adam R, et al. Posthepatectomy liver failure: a definition and grading by the International Study Group of Liver Surgery (ISGLS). Surgery. 2011 May;149(5): 713-24. 
18. Koch M, Garden OJ, Padbury R, Rahbari NN, Adam R, Capussotti L, et al. Bile leakage after hepatobiliary and pancreatic surgery: a definition and grading of severity by the International Study Group of Liver Surgery (ISGLS). Surgery. 2011 May;149(5):680-8.

19. Nishio $H$, Nagino $M$, Nimura $Y$. Surgical management of hilar cholangiocarcnima: the Nagoya experience. HPB (Oxford). 2005;7(4):259-62.

20. Unno M, Katayose Y, Rikiyama T, Yoshida H, Yamamoto K, Morikawa K, et al. Major hepatectomy for perihilar cholangiocarcinoma. J Hepatobiliary Pancreat Sci. 2010;17(4):463-9.

21. van Gulik TM, Kloek JJ, Ruys AT, Busch ORC, van Tienhoven GJ, Lameris JS, et al. Multidisciplinary management of hilar cholangiocarcinoma (Klatskin tumor): extended resection is associated with improved survival. Eur J Surg Oncol. 2011;37(1):65-71.

22. Cho MS, Kim SH, Park SW, Lim JH, Choi GH, Park JS, et al. Surgical outcomes and predicting factors of curative resection in patients with hilar cholangiocarcinoma: 10-year single-institution experience. J Gastrointest Surg. 2012;16(9):1672-9.

23. Nuzzo G, Giuliante F, Ardito F, Giovannini I, Aldrighetti L, Belli G, et al. Improvement in perioperative and long-term outcome after surgical treatment of hilar cholangiocarcinoma: results of an Italian multicenter analysis of 440 patients. Arch Surg. 2012;147(1):26-34

24. Neuhaus P, Thelen A, Jonas S, Puhl G, Denecke T, Veltzke-Schlieekere W, et al. Oncological superiority of hilar en bloc resection for the treatment of hilar cholangiocarcinoma. Ann Surg Oncol. 2012;19(5):1602-8.

25. Nagino M, Ebata T, Yokoyama Y, Igami T, Sugawara G, Takahashi Y, et al. Evolution of surgical treatment for perihilar cholangiocarcinoma. A singlecenter 34-year review of 574 consecutive resections. Ann Surg. 2013;258(1): 129-40.

26. Higuchi R, Ota T, Yazawa T, Kajiyama H, Araida T, Furukawa T, et al. Improved surgical outcomes for hilar cholangiocarcinoma: changes in surgical procedures and related outcomes based on 40 years of experience at a single institution. Surg Today. 2016:46(1):74-83.

27. Kimura N, Young AL, Toyoki Y, Wyatt Jl, Toogood GJ, Hidalgo E, et al. Radical operation for hilar cholangiocarcinoma in comparable Eastern and Western centers: outcome analysis and prognostic factors. Surgery. 2017; 162(3):500-14

28. Ratti F, Cipriani F, Fiorentin G, Salinas CH, Catena M, Paganelli M, et al. Management of hilum infiltrating tumors of the liver: the impact of experience and standardization on outcome. Dig Liver Dis. 2019;51(1):13541.

29. Lurje G, Bednarsch J, Czigany Z, Lurje I, Schlebusch IK, Boecker J, et al. The prognostic role of lymphovascular invasion and lymph node metastasis in perihilar and intra-hepatic cholangiocarcinoma. Eur J Surg Oncol. 2019;45(8): 1468-78.

30. Sano T, Shimada K, Sakamoto Y, Ojima H, Esaki M, Kosuge T, et al. Prognosis of perihilar cholangiocarcinoma: hilar bile duct cancer versus intrahepatic cholangiocarcinoma involving the hepatic hilus. Ann Surg Oncol. 2008;15(2): 590-9.

31. Kobayashi A, Miwa S, Nakata T, Miyagawa S. Disease recurrence patterns after R0 resection for hilar cholangiocarcinoma. Br J Surg. 2010;97(1):56-64.

32. Murakami Y, Uemura K, Sudo T, Hashimoto Y, Nakashima A, Kondo N, et al. Prognostic factors after surgical resection for intrahepatic, hilar, and distal cholangiocarcinoma. Ann Surg Oncol. 2011;18(3):651-8.

33. Lee JH, Hwang DW, Lee SY, Park K, Lee Y. The proximal margin of resected hilar cholangiocarcinoma: the effect of microscopic positive margin on long-term survival. Am Surg. 2012;78(4):471-7.

34. Groot Koerkamp B, Wiggers JK, Allen PJ, Besselink MG, Blumgart LH, Busch $\mathrm{ORC}$, et al. Recurrence rate and pattern of perihilar cholangiocarcinoma after curative intent resection. J Am Coll Surg. 2015;221(6):1041-9.

35. Komoya K, Ebata T, Yokoyama Y, Igami T, Sugawara G, Mizuno T, et al. Recurrence after curative-intent resection of perihilar cholangiocarcinoma: analysis of a large cohort with a close postoperative follow-up approach. Surgery. 2018;163(4):732-8.

36. Buettner S, van Vugt JLA, Gaspersz MP, Coelen RJS, Roos E, Labeur TA, et al. Survival after resection of perihilar cholangiocarcinoma in patients with lymph node metastases. HPB (Oxford). 2017;19(8):735-40.

37. Dinant S, Gerhards MF, Busch ORC, Obertop H, Gouma DJ, van Gulik TM. The importance of complete excision of the caudate lobe in resection of hilar cholangiocarcinoma. HPB (Oxford). 2005;7(4):263-7.

38. Bhutiani N, Scoggins CR, McMasters KM, Ethun CG, Poultsides GA, Pawlik $\mathrm{TM}$, et al. The impact of caudate lobe resection on margin status and outcomes in patients with hilar cholangiocarcinoma: a multi-institutional analysis from the US Extrahepatic Biliary Malignancy Consortium. Surgery. 2018;163(4):726-31.

39. de Jong M, Marques H, Clary BM, Bauer TW, Marsh JW, Ribero D, et al. The impact of portal vein resection on outcomes for hilar cholangiocarcinoma. Cancer. 2012;118(19):4737-47.

40. Nakanishi Y, Tsuchikawa T, Okamura K, Nakamura T, Tamoto E, Murakami S, et al. Prognostic impact of the site of portal vein invasion in patients with surgically resected perihilar cholangiocarcinoma. Surgery. 2016;159(6):15119.

41. Hemming AW, Mekeel K, Khanna A, Baquerizo A, Kim RD. Portal vein resection in the management of hilar cholangiocarcinoma. J Am Coll Surg. 2011;212(4):604-13.

42. Hoffmann K, Luible S, Goeppert B, Weiss KH, Hinz U, Büchler MW, et al. Impact of portal vein resection on oncologic long-term outcome in patients with hilar cholangiocarcinoma. Surgery. 2015;158(5):1252-60.

\section{Publisher's Note}

Springer Nature remains neutral with regard to jurisdictional claims in published maps and institutional affiliations.
Ready to submit your research? Choose BMC and benefit from:

- fast, convenient online submission

- thorough peer review by experienced researchers in your field

- rapid publication on acceptance

- support for research data, including large and complex data types

- gold Open Access which fosters wider collaboration and increased citations

- maximum visibility for your research: over $100 \mathrm{M}$ website views per year

At $\mathrm{BMC}$, research is always in progress.

Learn more biomedcentral.com/submissions 